\title{
Research on Predicting Slack Flow of Oil Pipelines in Undulated Areas with Large Fall
}

\author{
J.N. Zhang, H. Lan \\ PetroChina Pipeline Research \& Development Center \\ China
}

\begin{abstract}
Pipelines in more undulated areas are likely to have crossing points in pipeline transportation as oil throughput varies. This is to say that the potential energy of oils, from the peak to the terminal, is possibly higher than energy required for overcoming friction factor in oil movement, thus producing slack flow in pipes after the peak and accelerating partial flow velocity to consume remaining energy. Existed slack flow will be problem-prone like increased surge pressure, slow response to post-peak accident and vibration incurred by repeated occurrence and collapse of the steam bubble, when there are separation and crash of the liquid column in sudden change of the liquid flow speed. Therefore, targeted measures are necessary for avoiding slack flow. This text, for the first time, develops a parameter calculation model based on mechanism and characteristics of slack flow, proposes technology of predicting characteristics of the slack flow of pipelines in hilly areas with large fall and correctly predicts the defined parameters for the slack flow, including position, length, steam space volume, air space ratio and oil flow speed.
\end{abstract}

Keywords-large fall; slack flow; oil pipeline; mechanism; characteristic parameter

\section{INTRODUCTION}

Due to complicated landform in China, pipes are unavoidably laid through undulated areas with large fall and many oil pipelines are confronted with adverse effects from such large fall, such as Shilan Crude Oil Pipeline, Santanghu Crude Oil Pipeline, Western Product Oil Pipeline, Huatugou-Golmud Oil Pipeline, Lanzhou-Chengdu-Chongqing Product Oil Pipeline and Sino-Myanmar Crude Oil Pipeline. These pipelines, if unprotected in the undulated and large-fall sections in into the gas bag, which will greatly lower the spreading speed of pressure wave to make surge analysis process and control more complicated. Gas bag may also contribute to the separation of liquid column inside the pipe; in case of a surge, the pressurized surge will burst the gas bag formed of vapors, liquid column in upstream and downstream meets in the high speed and will possibly bring great pressure boost to make the pipeline pressure exceed the limit.

To remove potential threats to pipeline incurred by large-fall landform, currently four common control methods are available:

(1) Establish a pressure reducing station. In normal pipeline operation, pressure-drop of reducing valve is applied to increase friction of the downhill section, to prevent flow pressure from going too high. Unnecessary energy can be removed by the reducing valve to avoid high-point

\author{
J.J. Li \\ Civil Aviation University of China \\ China
}

mountainous areas, will make so much trouble to design and operation management.

(1) As the elevation difference of the downhill section is much bigger than on-way resistance under normal oil transportation, it makes flow pressure overhigh at middle and low points in operation thus causing the ultrahigh hydrostatic pressure [1].

(2) Without any pre-measure, slack flow will be formed in the high points of the downhill section. The oil flow, after crossing over the peak, can not only overcome any resistance to reach the end as a result of natural large-fall landform, but also remain certain potential energy. Therefore, without energy dissipation, oil flow will accelerate to add resistance and to eliminate remained potential energy. Accelerated oil flow in pipes will develop slack flow[2]. Slack flow is a flow pattern that the liquid energy can automatically regulate. When there is more-than-needed energy in pipeline system, the liquid will change its dynamic nature, which will change the flow pattern and add more resistance to balance energy of the pipeline system. Slack flow will do harm to the pipeline: (1) bring liquid column separation and pipeline vibration; (2) if the gas enters into the downstream pumping station, the pump may have cavitation or even liquid cutoff, further damaging equipments inside the station; (3) it will slow down normal production schedule and make pre-warning and positioning on any potential pipeline leakage accident difficult.

(3) When pressure around the high points where pipes are laid in the large-fall areas, is lower than saturated vapor tension of oils transported, liquid will be gasified and develop

gasification and slack flow. Reducing valve is closed in pipeline shutdown to cut off static pressure [3].

(2) Use of reducer pipe. Reducer pipe is used after the crossing point to increase on way friction by reducing the pipe diameter, to further lower flow pressure of the low point [4].

(3) Change of pipe thickness. Increase the thickness of pipes at low point to ensure safety.

(4) Pipeline operation under slack flow mode. This method will not only reduce flow pressure borne by the pipeline after crossing point, but also the investment of pressure reducing station. This method is recommended for high points that are at end of the pipeline and have no pump station.

From studies over calculation model and software of large-fall slack flow in China and at abroad, the simulation 
technology of large-fall slack flow is yet far from being perfect. First, Domestic and overseas researches on influence of backpressure as incurred by large-fall landform on occurrence of bubble crash of slack flow remain blank[5]; second, international researches related to slack flow model are mainly and gradually developed from slug flow. The liquid holdup of slug flow decides the calculation of the pressure drop of the slug flow. Gregory and others (1978)[6] studied effect of gas-liquid speed on air space ratio of slug flow; Malnes(1982) and Ferschneider(1983)[7]considered the effect of liquid properties; Andreussi and Bendiksen(1989)[8], Felizola and Shoham(1995)[9], Nuland (1997)[10], and Gomez(2000)[11] studied the effect of pipeline dip angle on air space ratio of slugs. However, these researches were mostly the fundamental experiments which mainly resulted the experimental relations with poor universal performance.

In terms of related software, pressure of single-phase flow software such as TLNET will be reduced to a very negative value in gasification calculation, which is against the physical rule; SPS uses centralized void model to work out gasification, integrates the gas space in every node of pipe sections and obtains incorrect results, which will not give slack flow length and gas space volume. Multi-phase flow software like PIPEPHASE, PIPEFLOW and PIPESIM exits must be multi-phase during simulation, and are required to be given in advance the air space ratio. Black oil software used by the software cannot work out the single liquid-phase pipeline. Calculation results of OLGA should be more discussed; the software must be given air space ratio first. It therefore indicated that, internationally or domestically, there is no model or software that can correctly calculate characteristics of slack flow of large-fall pipelines in undulated area at present.

This text, from a view of fundamental principles of fluid mechanics, integrates functionally models of open channel flow and pipe flow, to thoroughly consider parameters of the pipeline, liquid and equipment as well as effects of inter-phase dynamic and quality transfer and other factors. This text therefore establishes, for the first time, calculation model for analyzing characteristics of pipelines laid in undulated area with large fall.

\section{NUMERICAL MODEL}

Considering complicated slack flow mechanism, following assumptions are given prior to modeling:

(1) Temperature drop during gasification is not considered;

(2) Inter-phase friction loss or partial resistance is not considered;

(3) Variation of oil flow density during gasification is not considered.

For large-fall oil pipelines, oils property, vertical section data of the pipeline and data of equipments used along the pipeline can be comprehensively considered to judge pressure of which part of pipeline is lower than saturated steam pressure of the crude oil and if there is any gasification, to further confirm the location and length of slack flow along the pipeline route.
Some scholars considered to calculate pipe segments with slack flow as the open channel flow. However, the flow process of slack flow pipeline shall not be confirmed that the vapour liquid has same speed or is same with the open channel flow. Therefore, by not considering the surface tension and viscous flow loss and neglecting the vapour phase momentum, we analogize the slack flow as the stratified flow $\left(U_{g} \neq U_{l}\right)$ of two-phase separated flow model, to list flow control equation for vapour and liquid respectively.

Vapour-phase continuing equation

$$
\frac{\partial}{\partial t}\left(\alpha \rho_{g}\right)+\frac{\partial}{\partial x}\left(\alpha \rho_{g} u_{g}\right)=\dot{m}
$$

Liquid-phase continuing equation

$$
\frac{\partial}{\partial t}\left[(1-\alpha) \rho_{l}\right]+\frac{\partial}{\partial x}\left[(1-\alpha) \rho_{l} u_{l}\right]=-\dot{m}
$$

Vapour-phase momentum equation

$$
\frac{\partial}{\partial t}\left(\alpha \rho_{g} u_{g}\right)+\frac{\partial}{\partial x}\left(\alpha \rho_{g} u_{g}^{2}\right)=-\alpha \frac{\partial p}{\partial x}-\alpha g \rho_{g} \sin \theta-\frac{\tau_{g} s_{g}}{A}-\frac{\tau_{i} s_{i}}{A}
$$

Liquid-phase momentum equation

$$
\frac{\partial}{\partial t}\left[(1-\alpha) \rho_{l} u_{l}\right]+\frac{\partial}{\partial x}\left[(1-\alpha) \rho_{l} u_{l}^{2}\right]=-(1-\alpha) \frac{\partial p}{\partial x}-(1-\alpha) g \rho_{l} \sin \theta-\frac{\tau_{S_{l}}}{A}+\frac{\tau_{i} S_{i}}{A}
$$

Where:

$t$ __ Time, s;

$x$ distance between infinitesimal section and the starting point of the pipeline, $\mathrm{m}$;

$u_{l} \_$Liquid-phase rate, $\mathrm{m} / \mathrm{s}$

-

$m$ __nter-phase quality exchange rate, $\mathrm{kg} / \mathrm{s}$;

$p$ __Pressure at a certain infinitesimal section of the pipeline, $\mathrm{Pa}$;

$g \_$Gravitational acceleration section, $\mathrm{m} / \mathrm{s} 2$;

$\theta$ __ Angel of infinitesimal section, ${ }^{\circ}$;

A___Pipeline sectional area, $\mathrm{m} 2$.

It is assumed that:

1) Due to relatively bigger $\alpha$ value of the slack flow pipeline, surface tension and pipe expansion are not counted;

2) Inter-phase viscous flow loss or inter-phase partial resistance is not considered;

3) Effect of inter-phase momentum exchange is neglected;

4) Rate of vapour phase, $u_{g}$ is 0 ;

5) Vapour-phase momentum is neglected.

Under assumed conditions, control equation of the slack flow pipeline is turned into: 
Vapour-phase continuing equation:

$$
\frac{\partial}{\partial t}\left(\alpha \rho_{g}\right)=\dot{m}
$$

Liquid-phase continuing equation:

$$
\frac{\partial}{\partial t}\left[(1-\alpha) \rho_{l}\right]+\frac{\partial}{\partial x}\left[(1-\alpha) \rho_{l} u\right]=-\dot{m}
$$

Comprehensive momentum equation:

$$
\frac{\partial}{\partial t}\left[(1-\alpha) \rho_{l} u\right]+\frac{\partial}{\partial x}\left[(1-\alpha) \rho_{l} u^{2}\right]=(1-\alpha)\left(\frac{\partial p}{\partial x}-g \rho_{l} \sin \theta-g \rho_{l} \frac{f u|u|}{2 D}\right)
$$

Where: $u \_$Rate of a certain infinitesimal section of the pipeline, $\mathrm{m} / \mathrm{s}$;

\section{$f$ _ Fanning friction factor;}

Make the matrix of the equation and obtain the characteristic root to work out the wave rate, $a$ of the vapour-liquid phase flow for slack flow pipeline as:

$$
\begin{aligned}
& a^{2}=\frac{C_{3}}{C_{1}+C_{2}}=\rho_{l}^{-1}\left(\frac{\alpha}{\rho_{g} a_{g}^{2}}+\frac{1-\alpha}{\rho_{l} a_{l}^{2}}\right)^{-1} \\
& \quad C_{1}=\frac{\alpha}{\rho_{g} a_{g}^{2}} \quad C_{2}=\frac{1-\alpha}{\rho_{l} a_{l}^{2}} \quad C_{3}=\frac{1}{\rho_{l}}
\end{aligned}
$$

It indicates that, the spreading speed of the surge wave of the slack flow pipeline will be smaller than vapour-phase wave rate (generally $\alpha>0.1$ ). In case of a surge accident, if there is gasification or slack flow in steady operation in the pipeline, the spreading speed of the surge wave of each point inside the pipeline may vary significantly.

Based on characteristic root of the equation and equation (5) (7), equation sets for integrals of three characteristic lines can be obtained as follows:

$$
\begin{gathered}
\left\{\begin{array}{l}
\frac{d \alpha}{d t}+C_{1} \frac{d p}{d t}-b_{1}=0 \\
\frac{d x}{d t}=0
\end{array}\right. \\
\left\{\begin{array}{l}
\frac{d p}{d t} \pm \frac{\rho_{l} a(1-\alpha)}{A} \frac{d Q}{d t}-\rho_{l} a^{2} b_{1} \mp \rho_{l} a b_{3} \pm \frac{\rho_{l} a Q b_{2}}{A}-\rho_{l} a^{2} b_{2}=0 \\
\frac{d x}{d t}=u \pm a
\end{array}\right.
\end{gathered}
$$

Formula (9) represents the spreading rule of vapour-phase pressure wave along the characteristic line, $d x / d t=0$; Formula (10) represents spreading rule of the positive and negative pressure wave of the liquid phase along relevant characteristic line, $d x / d t=u \pm a$.

\section{MODEL VALIDATION}

As there is almost no field data in characteristic parameters of slack flow of large-fall pipelines, it is impossible to make direct validation on models and results forecasted. Considering that the commissioning and gas exhausting of large-fall pipelines are also the occurrence, development and disappearing process of slack flow, plus normally there are pressure monitors in stations or valve chambers along the route, therefore, this text integrates analysis \& calculation models of slack flow mechanism and characteristics as well as pipeline commissioning and exhausting processes, to indirectly validate correctness of the prediction technology.

Figure 1 is the Elevation Figure for a Large-fall Pipeline in China. In this figure below, A, B and C are three pressure monitoring points along the large-fall route.

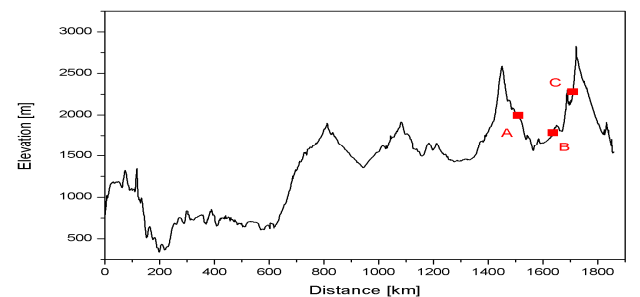

FIGURE 1. ELEVATION FIGURE FOR A LARGE-FALL PIPELINE IN CHINA.

By applying analysis and calculation model of slack flow mechanism and characteristics to commissioning and gas exhausting of the pipeline, pressure values of $A$ to $C$ points are calculated and compared to field data. See Figure 2 4.

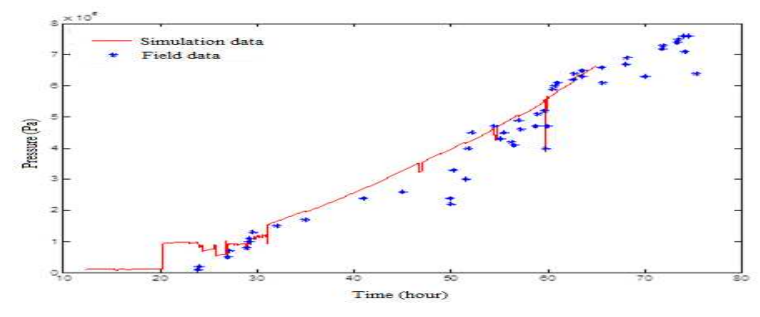

FIGURE 2. COMPARISON OF A-POINT PRESSURE VARIATION

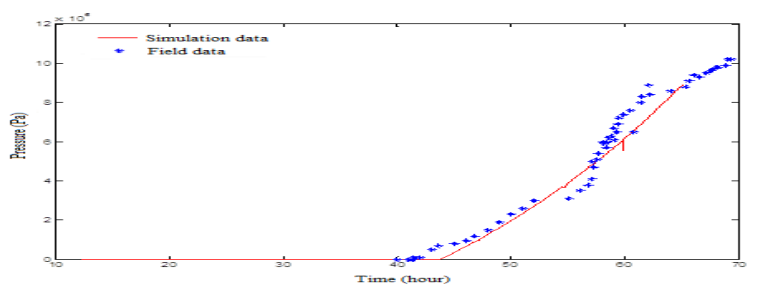

FIGURE 3. COMPARISON OF B-POINT PRESSURE VARIATION.

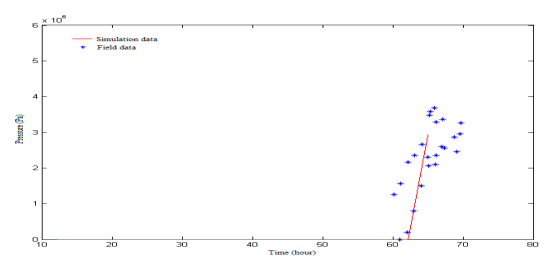

FIGURE 4. COMPARISON OF C-POINT PRESSURE VARIATION.

As we learned from above three figures, their pressure values tend to vary as the time and field data change, indicating that the analysis and calculation model of slack 
flow characteristics have high precision of prediction and correct results.

\section{NUMERICAL RESULTS}

Prediction model of slack flow is applied to Sino-Myanmar oil pipeline (domestic pipeline section), to predict and analyze its slack flow under different conditions of pipelines. Length, volume, liquid holdup and flow rate of liquid phase for every pipe segment of different oil throughput rate is analyzed respectively, with pressure of each pipe segment exit considered as $0.2 \mathrm{MPa}, \mathrm{MPa}$ and $1.0 \mathrm{MPa}$. Setting different exit pressures is to provide possible basis for future surge analysis and flow reduction inside the station.

Table 1 outlines total length of slack flow and gas space volume of each segment of 17 million ton/year pipeline.

TABLE I. SLACK FLOW OF 17 MILLION TON/YEAR PIPELINE.

\begin{tabular}{|c|c|c|c|c|c|c|c|}
\hline & & Termina & 1 0.2MPa & Termina & l 0.5MPa & Termin & 11.0MPa \\
\hline & $\begin{array}{l}\text { Oil throughput } \\
\text { (10-thousand } \\
\text { ton/year }\end{array}$ & $\begin{array}{l}\text { Total length of } \\
\text { slack flow } \\
(\mathrm{km})\end{array}$ & $\begin{array}{c}\text { Total volume of } \\
\text { gas space } \\
\left(\mathrm{m}^{3}\right)\end{array}$ & $\begin{array}{l}\text { Total length of } \\
\text { slack flow } \\
(\mathrm{km})\end{array}$ & $\begin{array}{l}\text { Total volume of } \\
\text { gas space } \\
\left(\mathrm{m}^{3}\right)\end{array}$ & $\begin{array}{l}\text { Total length of } \\
\text { slack flow } \\
(\mathrm{km})\end{array}$ & $\begin{array}{c}\text { Total volume of } \\
\text { gas space } \\
\left(\mathrm{m}^{3}\right)\end{array}$ \\
\hline Baoshan-Midu & 1700 & 6.06 & 1578.84 & 6.01 & 1556.65 & 5.93 & 1517.94 \\
\hline Midu-Lufeng & & 4.56 & 1486.93 & 3.82 & 1359.67 & 3.22 & 1246.95 \\
\hline Lufeng-Qujing & & 2.86 & 489.76 & 2.51 & 422.71 & 2.27 & 364.56 \\
\hline Qujing-Tongzi & 700 & 0.35 & 71.75 & 0 & 0 & 0 & 0 \\
\hline Tongzi-Chongqing & & 6.79 & 1013.27 & 6.18 & 952.65 & 5.79 & 888.31 \\
\hline
\end{tabular}

The table above indicated that, length of slack flow and gas space volume decreases as the exit pressure of pipe segments or oil throughput increases.

Taken terminal control pressure, $0.2 \mathrm{MPa}$ of Ruili-Mangshi pipe segment as an example, a slack flow parameter diagram is made as Figure 5 below. In this figure, blue line represents the landform; orange line shows hydraulic grade line; red line shows liquid holdup and green line shows the oil flow rate. Regions where red and green lines overlap are gasification area (slack flow), indicating that when there is a pipeline slack flow, oil flow rate increases as liquid holdup decreases.

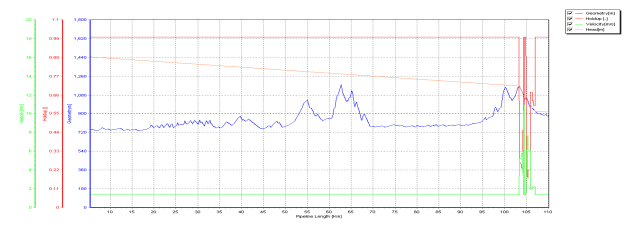

FIGURE 5. DIAGRAM OF SLACK FLOW PARAMETERS UNDER EXTREME CONDITIONS (17 MILLION TONS/YEAR) [RUILI-MANGSHI].

\section{CONCLUSION}

This text, from a view of fundamental principles of fluid mechanics, integrates functionally models of open channel

flow and pipe flow, to thoroughly consider parameters of the pipeline, liquid and equipment as well as effects of inter-phase dynamic and quality transfer and other factors. This text therefore establishes, for the first time, calculation model for analyzing characteristics of pipelines laid in undulated area with large fall.
Models can be used to predict distribution and disappearing of slack flow of on-way pipelines, to provide basis for control of pipelines over the slack flow and further reduce risks of pipeline gasification.

\section{References}

[1] Yang Xiaoheng. Design and Management of Oil Pipelines[M]. Beijing: China University of Petroleum Press. 2006:58.

[2] Kang Zhengling \& Gong Jing. Control of Pressure Reducing Station[J]. Oil-Gas Field Surface Engineering. 2002. (5):46-47.

[3] Wang Jianjian \& Li Yong. Application of Relieve Valve in Ku-Shan Oil Transportation Pipeline[J]. General Machinery. 2004. (5). 47-49.

[4] Li Jiaqiang. Optimization Design of Pipe Diameter of Large-fall Processes in Liuping-Yaodian Oil Pipeline[J]. Oil \& Gas Storage and Transportation. 2006. (1). 18-20+67+7.

[5] Bacon,R.P., Scott, D.M., Thorpe, R.B.. Large bubbles attached to spargers in downwards two-phase flow[J]. Int. J. Multiphase Flow, 1995a, 21: 949-959.

[6] Gregory, G.A., Nicholson, M.K., Aziz, K.. Correlation of liquid volume fraction in the slug for horizontal gas-liquid slug flow[J]. Int. J. Multiphase Flow, 1978, 4: 33-39.

[7] Malnes, D.. Slug flow in vertical horizontal and inclined pipes[D]. Institute for Energy Technology, Keller, Norway. 1982.

[8] Ferschneider, G. Ecoulement diphasiques gas-liquide a poches et a bouchons en conduits[J]. Revue de Institute Francais du Petrole, 1983, 38: 153-182.

[9] Felizola, H., Shoham, O. A unified model for slug flow in upward inclined pipes[J]. ASME J. Energy Resour. Technol. 1995, 117: 1-6.

[10] Nuland, S.,Malvik, I.M., Valle, A., Hende, P.. Gas fractions in slugs in dense-gas two-phase flow from horizontal to 60 degrees of inclination[C]. The 1997 ASME Fluids Engineering Division Summer. 1997.

[11] Gomez, L.E., Shoham, O., Taitel, Y.. Prediction of slug liquid holdup: horizontal to upward vertical flow[J]. Int. J. Multiphase Flow, 2000, 26: $517-521$. 